\title{
Neurometabolic correlates of depression and disability in episodic cluster headache
}

\author{
Christian L. Seifert • Michael Valet • Volker Pfaffenrath • \\ Henning Boecker · Katharina V. Rüther • \\ Thomas R. Tölle $\cdot$ Till Sprenger
}

Received: 15 May 2010/Accepted: 9 August 2010/Published online: 25 August 2010

(C) The Author(s) 2010. This article is published with open access at Springerlink.com

\begin{abstract}
A close association between pain, depression and disability has been shown. However, the neurometabolic correlates of this association have been barely investigated in disease states. Episodic cluster headache is a severe headache syndrome and represents a suitable disease model for the investigation of episodic pain. The aim of this study was to explore the relationship between depression and disability as well as pain scores and brain metabolism in patients with cluster headache during the disease period with repetitive pain attacks, but outside an acute attack. Thirteen patients with cluster headache underwent 2-[fluorine-18]-fluoro-2-
\end{abstract}

C. L. Seifert $(\varangle) \cdot$ M. Valet $\cdot$ K. V. Rüther

T. R. Tölle $\cdot$ T. Sprenger

Neurologische Klinik und Poliklinik,

Klinikum rechts der Isar, Technische Universität München,

Ismaninger Str. 22, 81675 München, Germany

e-mail: c.seifert@lrz.tu-muenchen.de

V. Pfaffenrath

Neurologische Gemeinschaftspraxis,

Leopoldstrasse 59, München, Germany

H. Boecker

Nuklearmedizinische Klinik,

Klinikum rechts der Isar,

Technische Universität München, München, Germany

H. Boecker

Radiologische Uniklinik,

Friedrich-Wilhelms-Universität Bonn,

Bonn, Germany

\section{T. Sprenger}

Department of Neurology, Headache Group,

University of California,

San Francisco, USA

e-mail: till.sprenger@ucsf.edu
deoxy-D-glucose positron emission (FDG-PET) and completed questionnaires on depression and disability as well as a pain visual analogue rating scale (VAS). A positive correlation between the depression scores and glucose metabolism was observed in the insular cortex. A positive correlation between the pain disability scores and brain metabolism was detected in the amygdala. The same applied to the pain visual analogue rating scores. Our data underline the association between severe episodic pain, depression and disability. In addition to this clinical observation, our results stress the importance of the insula and amygdala in pain processing and suffering.

Keywords Cluster headache - Depression - Disability . Pain intensity · FDG-PET

\author{
Abbreviations \\ SVcorrected Small volume corrected \\ FWE Family wise error
}

\section{Introduction}

Brain correlates of experimental pain have been extensively investigated by modern imaging techniques such as functional magnetic resonance imaging (fMRI) and positron emission tomography (PET) $[2,58]$. Pain is a complex sensory phenomenon with many different aspects which have been investigated using those techniques. Most of these imaging studies used paradigms with laser, contact heat $[8,78]$ or electrical stimulation $[16,38]$ to provoke pain. Another possibility is the topical application of capsaicin $[45,54]$. However, experimentally induced pain as a 
model for clinical pain is limited because of the side effects of the stimulation procedure itself, e.g., burns due to stimulation temperatures above $50^{\circ} \mathrm{C}$. Hence, extremely severe pain can not be evoked in humans under experimental conditions for ethical and safety reasons. Thus, the investigation of long-term mood alterations or disability, especially in the context of severe repetitive pain attacks or chronic pain, is problematic. However, the relevance and high prevalence of depression and disability has been documented for every facet of clinical pain in many studies [47] and also in primary headache syndromes [7, 11, 27].

Depression and impaired quality of life are highly important variables in pain research because of their complex interactions with pain and vice versa [11,24]. Not only a clinical [32], but also a neurometabolic overlap between depression and pain has been hypothesized [30]. However, the neurometabolic correlates of depression and disability in severe pain syndromes have been barely investigated so far.

Cluster headache $(\mathrm{CH})$ is a primary headache disorder with attacks typically recurring in bouts. The duration of the attacks varies between 15 and 180 min and the attacks are associated with a variety of cranial autonomic symptoms [74]. The pain is usually restricted to one side of the face and confined to the orbital, supraorbital and temporal regions [34]. A strong circadian periodicity with attacks often occurring at night is another hallmark of the disorder [60]. $\mathrm{CH}$ is very disabling with a high individual and socioeconomic burden, especially during periods of frequent attacks [35]. Because of the excruciating pain attacks, $\mathrm{CH}$ has also been called suicide headache [75].

In this study, we investigated patients suffering from $\mathrm{CH}$ as a clinical model for severe episodic pain and aimed to determine brain areas in which the metabolism relates to the burden of depressive symptoms, disability and pain intensity using a correlative approach with 2-[fluorine-18]-fluoro-2deoxy-D-glucose positron emission tomography (FDGPET).

\section{Materials and methods}

\section{Patients}

Thirteen male patients with strictly side-locked episodic cluster headache (mean age 44.2 years, SD 8.89) with no other prediagnosed neurological or psychiatric disease were included in the study. The patients indicated an average attack duration of $103 \mathrm{~min}$ and an average frequency of 2.5 attacks per day. The mean duration of their cluster headache bouts was 16 weeks. The study was approved by the local ethics committee as well as the German Radiation Protection Commission, and conforms with the Declaration of Helsinki. All participants gave written informed consent after a detailed explanation of the procedures. All patients met the criteria of the International Headache Society (IHS) for episodic cluster headache confirmed by two neurologists specialized in headache. The PET scans were acquired during the period with repetitive cluster headache attacks ("in bout"), but without acute pain during the scanning. The last attack occurred $6 \mathrm{~h}$ or more before the PET scanning to ascertain that patients were interictal. At the time of scanning, the patients were in the bout period (repetitive pain attacks) for at least 1 week. Due to the severity of the headache syndrome, all patients were allowed to continue the use of their prophylactic medication. Eight patients were taking verapamil, one patient lithium, one patient a combination of lithium and verapamil, one patient ergotamine and two patients had no prophylactic medication. Clinical magnetic resonance imaging of the brain was unremarkable in all patients. Some of the patient data were previously included in a study of our group comparing the brain metabolism in cluster headache patients with the metabolism in healthy volunteers [68].

\section{Data acquisition and preprocessing}

All study participants were imaged using FDG-PET in threedimensional mode with septa retracted on a Siemens ECAT EXACT HR + Scanner (CTI, Knoxville, TN, USA). A neckshield (NeuroShield, Scanwell Systems, Lavigne St. Montreal, Canada) was used to reduce random count rates. The patients were positioned with the head parallel to the canthomeatal line within the gantry. An antecubital vein cannula was used to administer the tracer as an i.v. bolus $(185 \mathrm{MBq}$ ${ }^{18}$ F-FDG for each scan). During the scanning, all subjects rested and had their eyes closed. A sequence of three frames of 10 min each was started and afterwards combined into a single frame. After attenuation correction by a standard ellipse-fitting method, the PET data were reconstructed by filtered back projection with a Hamm filter (cut-off frequency 0.5 cycles/projection element) into 60 image planes and into a $128 \times 128$ pixel image matrix (pixel size $2.1 \times 2.1 \mathrm{~mm}$ ).

As $\mathrm{CH}$ is a strictly lateralized headache syndrome [34], the PET scans of the patients with left-sided headache $(n=6)$ were mirrored in the axial plane to be able to analyse all cluster headache patients as one group. Thereafter, all images were transformed into standard stereotactic space (Talairach space) by linear scaling and non-linear warping using the NEUROSTAT program [51, 52]. Normalization was performed with NEUROSTAT instead of the statistical parametric mapping software (SPM), because the latter program does not provide a FDG template, and normalization of FDG data to the $\mathrm{H}_{2}^{15} \mathrm{O}$-PET template of SPM has been shown to be inaccurate [28]. Spatial smoothing was performed with a Gaussian kernel of $8 \mathrm{~mm}$ full width at half maximum (FWHM). 


\section{Questionnaires}

The participants were instructed to fill out the following questionnaires directly before injection of the radioactive tracer and the PET scanning:

\section{CES-D}

The Center for Epidemiological Studies Depression Scale (CES-D) has been frequently used to assess depressive symptoms in the general population. This is also true for its German version [61]. It is part of the German pain questionnaire, which has been compiled by the German chapter of the International Association for the Study of Pain [56], and is the most widely used instrument to measure depressive symptoms in the context of episodic or chronic pain in Germany. The CES-D generates a total score ranging from 0 to 60 . Scores $\geq 16$ indicate clinically significant levels of depressive symptoms. At this cut-off, the sensitivity is $100 \%$ and the specificity is $88 \%$ for a major depressive disorder [6, 62]. The CES-D includes items about the frequency of depressive symptoms, including somatic symptoms and interference with interpersonal interactions, experienced during the past week. Positive and negative experiences are indicated on a 4-point Likert scale: $0=$ Rarely or None of the Time (Less than 1 day), $1=$ Some or Little of the Time (1-2 days), $2=$ Occasionally or Moderate Amount of the Time (3-4 days), and 3 = Most or All of the Time (5-7 days). The CES-D total score is typically generated by summation of the individual item scores. Four items assess the presence of positive feelings and are rated inversely.

\section{Pain disability index}

The Pain Disability Index (PDI) is a measure of painrelated disability, assessing perceived impairment of functioning across seven areas of daily functioning. The PDI asks subjects to rate the degree to which chronic pain interferes with activities in each of the domains: family/ home responsibilities, recreation, social activity, occupation, sexual behavior, self-care, and life-supporting activities. The total range is $0-70$ points with higher scores indicating more perceived disability [79]. The PDI is an internally consistent ( $\alpha=0.86$ ) measure of perceived disability with good concurrent, criterion-related and discriminative validity in a variety of inpatient and outpatient pain populations $[59,71,72]$.

\section{VAS-rating}

We used a VAS rating scale (0-10) for pain ratings [14], which provides a scale for the subjective assessment of the pain intensity and consists of a straight line, the limits of which carry a verbal description of each extreme of the symptom to be evaluated (no pain and unbearable pain). Patients were instructed to indicate their average perceived pain intensity of the cluster headache attacks during the last attacks of the preceding month. As indicated above, the patients were out of an attack at the time of the scanning.

Statistics

\section{Questionnaire data}

Correlations between the scores of the separate questionnaires were calculated with the Spearman Rho test. $P<0.05$ was considered to be significant.

\section{Statistical parametric mapping analysis/correlation analysis}

Brain metabolism was correlated with psychophysical data as previously described [20, 65, 73]. Covariation analyses of scans and CES-D scores, as well as PDI and VAS scores, were conducted with SPM2 (Wellcome Department of Imaging Neuroscience, London, UK) using MATLAB 6.5 (Mathworks Inc., Sherborn, MA, USA). We expected covariation of the psychophysical scores with the metabolism in brain regions that have been previously shown to be involved in pain processing (thalamus, S1, S2, insula, amygdala, anterior cingulate cortex, parietal and prefrontal cortex) [2, 58] and the covariation analyses were confined to these regions. The resulting maps of $t$ statistics were transformed to the unit normal distribution and thresholded at $P<0.001$, uncorrected, for all contrasts. The minimal cluster extension (number of adjacent significant voxels) was set at 15 contiguous voxels passing the statistical threshold. Small volume correction using the family-wise error (FWE) approach $(P<0.05)$ was applied on the prespecified regions (spherical volumes of interest with a radius of $10 \mathrm{~mm}$ surrounding the activation center).

We also conducted subgroup covariation analyses excluding the patients on lithium therapy as lithium has been previously shown to alter the brain metabolism. These subgroup analyses were conducted in an identical way as described for the whole group of patients.

\section{Results}

Clinical/behavioural data

The mean duration of the bout before the FDG-PET investigation was 8 weeks with a standard deviation (SD) of 4 weeks. The mean of the VAS pain ratings for the last 


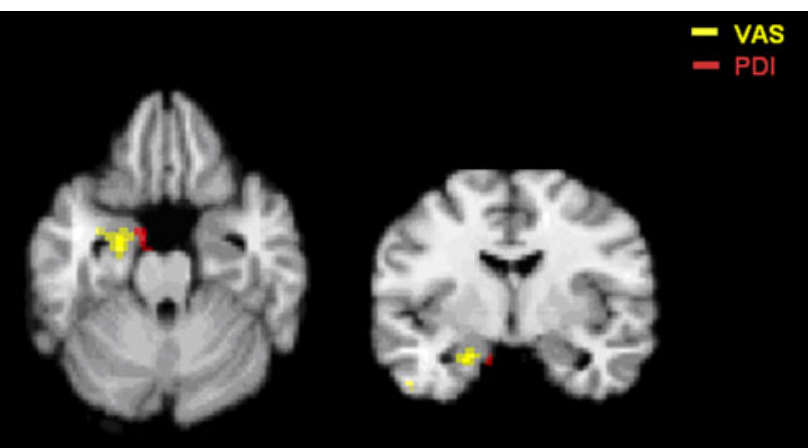

Fig. 1 Correlation analysis of VAS pain scores (yellow) and PDI scores (red) with FDG-PET signal thresholded at $P<0.001$. The statistical parametric maps are overlaid on a skull stripped normalized structural magnetic resonance image (MRI) in axial planes (average of 27 T1-weighted scans of the same individual from the Montreal Neurological Institute) as provided by the MRICRO program package (http://www.sph.sc.edu/comd/rorden/mricro.html). The MRI was stereotactically normalized with NEUROSTAT before overlay

4 weeks was 9.42 (SD 0.78), the mean PDI score was 33.31 (SD 19.5) and the mean CES-D score was 23 (SD 9.77). All but three of the patients had CES-D scores above the cut-off value of 16, indicating a significant level of depressive symptoms. There were no statistically significant correlations between the different scores/scales (e.g., between VAS and PDI). CES-D scores as well as PDI scores did not correlate with the duration of the bout. Follow-up CES-D scores "out of bout" in five of the patients indicated no depressive symptoms out of bout [the mean CES-D score out of bout was 5.6 (SD 5.1)].

\section{FDG-PET correlation with PDI and VAS}

We found a covariation of the FDG-PET signal and the subjective pain perception (VAS) and disability scores (PDI) in different subregions of the amygdala $(P<0.001)$. The brain metabolism in the laterobasal amygdaloid group (LB) was correlated with the VAS pain ratings, whereas a correlation with the PDI scores was found in the superficial group (SF) of the amygdala (Figs. 1, 2). The sites of covariation within the amygdala were lateralized (contralateral to the side of the cluster headache) for the VAS pain scores, but bilateral for the PDI scores. When lowering the significance level $(P<0.005)$, an additional trend of covariation (VAS scores) was observed in the ipsilateral amygdala.

The $P$ values and the statistical peak coordinates are listed in Table 1. The correlation coefficient was $r=0.807$ when correlating the PDI scores and $r=0.647$ when correlating the VAS scores with the FDG-PET signal in the amygdala at the local statistical peak (Spearman correlation).

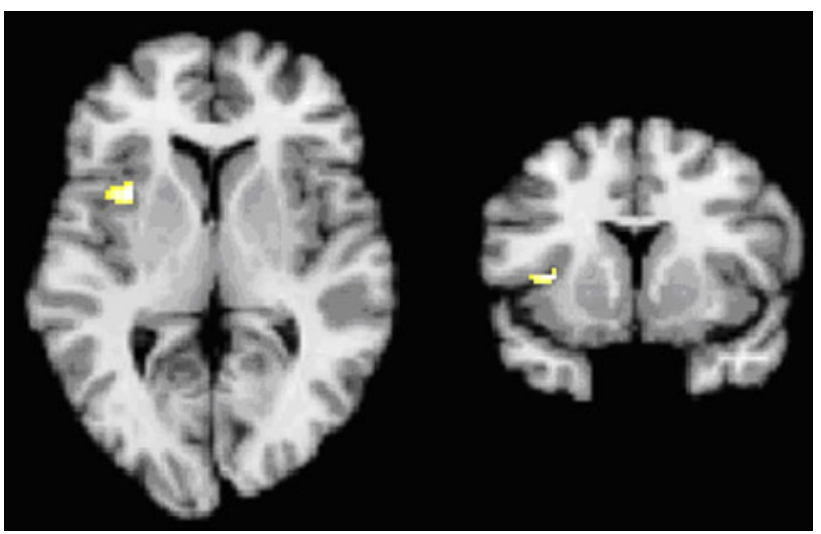

Fig. 2 Correlation analysis of CES-D with FDG-PET signal, thresholded at $P<0.001$. The statistical parametric map is overlaid on a skull stripped normalized structural magnetic resonance image (MRI) in axial planes (average of 27 T1-weighted scans of the same individual from the Montreal Neurological Institute) as provided by the MRICRO program package (http://www.sph.sc.edu/comd/rorden/ mricro.html). The MRI was stereotactically normalized with NEUROSTAT before overlay

Table 1 Statistical results of the covariation analysis of the FDGPET data and PDI as well as VAS scores

\begin{tabular}{|c|c|c|c|c|c|c|c|}
\hline \multirow[t]{2}{*}{ Amygdala } & \multirow{2}{*}{$\begin{array}{l}\text { Cluster- } \\
\text { size }\end{array}$} & \multicolumn{3}{|c|}{ Voxel level } & \multirow[t]{2}{*}{$x$} & \multirow[t]{2}{*}{$y$} & \multirow[t]{2}{*}{$z$} \\
\hline & & $Z$ & $P_{\text {uncorrected }}$ & $\begin{array}{l}P_{\mathrm{SV} \text { corrected }} \\
\text { (FWE) }\end{array}$ & & & \\
\hline \multirow[t]{3}{*}{ PDI } & 147 & 4.80 & $<0.001$ & $<0.001$ & 27 & 14 & -32 \\
\hline & & 4.60 & $<0.001$ & 0.001 & 18 & 2 & -32 \\
\hline & 31 & 4.13 & $<0.001$ & 0.004 & -9 & 0 & -20 \\
\hline VAS & 88 & 4.49 & $<0.001$ & 0.001 & -18 & -2 & -18 \\
\hline
\end{tabular}

$P$ values and centers of gravity for the significant clusters in the amygdala are indicated. The coordinates for the peak correlations are stated in Talairach space

The voxel-wise covariation analysis excluding the patients on lithium provided very similar results as compared to the analysis of the whole group. Covariation was again seen bilaterally in the amygdala for the PDI scores $(x /$ $y / z$ coordinate $29 / 16 /-29 ; z$ score $4.84 ; P<0.001$; cluster extension 239 voxels and $x / y / z$ coordinate $-9 /-7 /-25$; $z$ score 4.61; $P<0.001$; cluster extension 191 voxels) and unilaterally for the VAS scores $(x / y / z$ coordinate $-20 /$ $-5 /-20 ; z$ score 4.61; $P<0.001$; cluster extension 147 voxels).

\section{FDG-PET correlation with CES-D}

The covariation analysis of CES-D scores and the FDGPET signal yielded correlations in the anterior/middle insular cortex on the side contralateral to the cluster headache symptoms $\quad$ corrected $P$ value $=0.027$; 


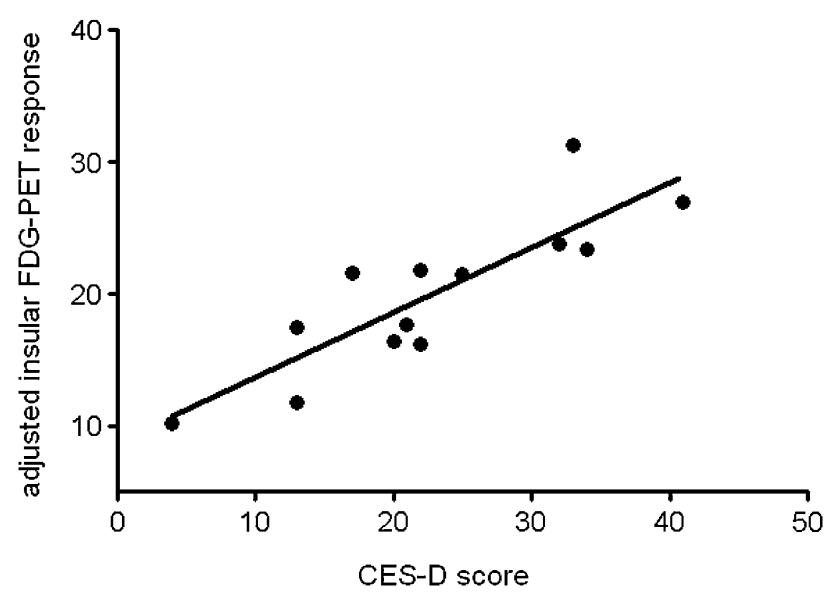

Fig. 3 Spearman correlation of the adjusted FDG-PET signal in the insula and the CES-D scores; $r=0.858$

$z$ score $=3.64$; peak $x / y / z$-coordinate $-34 / 14 / 7$; number of contiguous significant voxels: 24 voxels).

The correlation coefficient was $r=0.858$ for the correlation between CES-D scores and the FDG-PET signal in the insular cortex (Fig. 3).

When lowering the significance level $(P<0.01$, uncorrected), an additional trend of covariation (CES-D scores) was observed in the ipsilateral anterior/middle insular cortex and the sub-/perigenual ACC.

In the subgroup analysis excluding the patients on lithium therapy, the location of the covariation peak with the CES-D scores was almost identical as compared to the analysis of the whole patient group $(x / y / z$ coordinate $-32 /$ $14 / 7$; $z$ score $3.56 ; P<0.001$; cluster extension 18 ).

\section{Discussion}

We present FDG-PET data on episodic $\mathrm{CH}$ as a disease model for severe episodic pain and correlate these PET data with scores of pain intensity, the CES-D and PDI. Glucose is the major substrate for brain metabolism, and FDG-PET is, therefore, suitable for measuring the glucose metabolic pattern and detecting changes in local synaptic activity [63]. Correlation of brain metabolism with neuropsychological test scores is an approach to map underlying neuropsychological processes $[20,65,73]$. In contrast to methods recording short term changes in the context of pain processing, like fMRI or $\mathrm{H}_{2}^{15} \mathrm{O}$ PET, our approach focuses on prolonged changes in brain metabolism related to the repeated experience of severe pain, and these changes may be conceived as neuroplastic adaptations, leading to increased brain activity and glucose metabolism in specific regions [33].

As indicated above, patients continued their prophylactic medication. Because of the excruciating nature of $\mathrm{CH}$, it seemed unethical to ask the patients to stop their medication with the risk of worsening their headache frequency and severity. Theoretically, the medication, notably lithium, may impact the FDG metabolism. However, only two patients were on lithium at the time of scanning and the results were unchanged in the analysis with exclusion of these two patients. Moreover, lithium related changes in brain activity have been reported for the dorsomedial frontal cortex, cerebellum and lingual cortex [41], but not for any region observed to correlate with psychometric data in our study. As regards verapamil, no verapamil-induced changes in brain metabolism have been reported thus far in the literature. Altogether, we believe that the results are valid as we studied the patients while they were on their typical medication; thus, in the most naturalistic setting. Hence, the results reflect the metabolic substrates of depression, pain intensity and disability in patients as they are seen in clinical practice.

PET correlation with pain intensity and disability

The average VAS pain score of more than nine out of ten for the $\mathrm{CH}$ attacks during the previous 4 weeks illustrates the severity of $\mathrm{CH}$ and the usefulness of this disorder as a clinical model for severe episodic pain. It is intuitive that pain of such an intensity is accompanied by relevant psychophysiological symptoms, serious impairment of daily life, and disability. The PDI scores indicate such a severe disability in multiple aspects of life [15]. The observation that pain ratings and PDI scores are highly correlated with amygdalar metabolism can be regarded as evidence for a common psychophysiological basis of perceived pain intensity, and disability (PDI) represented in the amygdala. Regarding the PDI, this can be best explained by the convergent validity of this score with anxiety scores [50].

Amygdalar function and anatomy

As part of the limbic system, the amygdala is involved in emotional processing, including the evaluation of sensory information as pleasant or aversive [31]. The consolidation of memories of emotionally arousing experiences such as fear or disgust is also represented in the amygdala [49, 55]. Anatomical studies have suggested the presence of an intrinsic system of GABAergic neurons that acts as an interface between sensory afferents and brain stem-projecting neurons [13]. However, the human amygdala is no homogeneous anatomical structure [4]. Based on differences in cyto- and chemoarchitecture, it can be differentiated into the laterobasal amygdaloid group (LB), the centromedial group (CM), and the superficial group (SF) [1]. Results from previous neuroimaging studies [40, 80] suggest functional differences in the human amygdala 
similar to those of the animal amygdala, whereupon the LB is believed to play a crucial role in assigning emotional value to sensory stimuli [64]. The CM receives convergent information from other amygdaloid regions and sends efferent information to various subcortical structures, generating behavioural responses such as the modulation of autonomic activity $[21,43,44]$. The function of the SF has not been satisfactorily investigated so far in humans, but animal studies showed an involvement of this subregion in affective processing [29]. Response differences between LB, SF, and CM, have not been directly assessed in human functional neuroimaging studies so far, and specific functional properties of these subdivisions of the human amygdala are, therefore, unclear [4].

Pain and amygdala

The role of the amygdala in human pain processing is only partly understood. Bilateral lesions of the amygdala in monkeys cause reductions of opioid and cannabinoid induced antinociception [46]. This has been supported by the observation that experimental pain stimuli induce endogenous opioid release in the amygdala $[67,69,81]$. Responses to painful stimuli with a strong affective component have previously been reported in the amygdala [66], and a study investigating the lateralization of amygdalar activations in response to laser induced pain has shown symmetric activations [9]. We found an ipsilateral correlation of pain intensity ratings and amygdalar metabolism, but there was an additional contralateral trend, and our findings are, therefore, similar to the findings of the noted previous study with experimental pain stimulation [9], supporting the concept of bilateral amygdalar responses.

The finding of pain intensity coding in the amygdala is in agreement with a previous parametric fMRI study investigating amygdalar responses to experimentally induced painful stimuli of different intensities. In this study, Bornhovd et al. [10] showed a dependency of the amygdalar activation state and the intensity of the painful stimuli. As we found no correlation of pain intensity with typical sensory brain regions belonging to the lateral pain system, such as the primary or secondary somatosensory cortex, our data indicate that the amygdala may be particularly relevant in the intensity coding of clinical pain.

In our study, pain scores were correlated with the metabolism of the LB, whereas the PDI scores were linked to the SF, and although one has to be cautious regarding the spatial discrimination of different statistical maxima in small brain areas such as the amygdala in PET studies, our results suggest a differential correlative pattern of glucosemetabolism and pain intensity versus disability within the amygdala.

\section{Correlation between CES-D scores and PET data}

The CES-D scores indicate a clinically relevant depressive state during the bout period and are, therefore, suitable to investigate the relationship between pain associated depression and glucose metabolism [6]. The Center for Epidemiological Studies Depression Scale applied in this study has been previously used not only in clinical pain medicine, but has also been applied repetitively in functional imaging studies [23, 57] and population studies [37]. It has been suggested that in pain patients, the CES-D has a better sensitivity than the Beck Depression Inventory (81.8 vs. $68.2 \%$ ), and both questionnaires were shown to be able to discriminate between persons with and without major depression [26].

In a previous study on episodic cluster headache, none of the patients met diagnostic criteria for a mood disorder during the period preceding a bout. During the bout, however, the average Hamilton Depression Rating Scale (HDRS) score was 8.6, which was higher than in a control group of tension type headache patients with an average score of 6.5 , although the difference was not statistically significant [36]. HDRS scores between zero and seven are generally accepted to be within normal limits [25], and the scores in the cluster headache patients were somewhat higher than what is considered to be normal. Moreover, the authors acknowledged that the study design may have led them to underestimate the frequency of depressive disorders. This supports the view that depressive symptoms occur "in bout", whereas no such symptoms are evident "out of bout" — just like in our patient cohort. Another recent study reported Hamilton depression scores of eight or greater in $43 \%$ of chronic cluster headache patients [22] and we believe that it is conceivable that also shorter bouts of excruciating head pain, such as in episodic cluster headache, can produce transient alterations of mood and behaviour [76]. Considering our results and the results of the noted previous studies, it may be useful to consider pain related depression in a comprehensive treatment concept of $\mathrm{CH}$.

A correlation of CES-D scores and glucose metabolism was present in the insular cortex and, as a trend, also in the sub-/perigenual ACC. However, there was no covariation of depression scores with the neurometabolism in other parts of the brain thought to play a role in the pathogenesis of depression such as the prefrontal cortex [42, 48].

Insular cortex

The insular cortex is among the most frequently reported brain regions in neuroimaging studies on pain [77]. In primates, the insular cortex has numerous connections with the cerebral cortex, the basal ganglia and limbic structures [3]. The anterior and mid-insula are known to be active in response to a wide variety of somatic stimuli, including 
tactile [5, 17], vibratory [18], innocuous thermal [19], olfactogustatory [19], and pain [12, 18, 53, 78] and its function can be regarded as an interface between viscerosensory information preparation and its subliminal and conscious processing.

An increase of insular metabolism and a normalization after treatment of a major depressive disorder with SSRIs has been observed [39]. These authors suggested that suppression of insular activity may be necessary for the recovery from depression. Moreover, increased insular activation has been shown in patients with major depression as compared to healthy controls when anticipating painful stimuli [70]. It was inferred that the anticipatory brain response indicates hypervigilance to threats and might lead to maladaptive modulation of pain [70].

Taken together, our results stress the importance of the amygdala and insula in pain processing and suffering. The results also suggest that the insular glucose metabolism may predict depressive symptoms in episodic pain.

Acknowledgments We wish to thank the patients who participated in this experiment. We also thank Brigitte Dzewas and Coletta Kruschke for their technical assistance and the radiochemistry group for their reliable supply of radiopharmaceuticals. The study was supported by grants from the 'Deutsche Migräne und Kopfschmerzgesellschaft' (DMKG) and the Schulz-Fond. Dr. Sprenger is supported by the Deutsche Forschungsgemeinschaft (DFG, Project SP1215/1-1).

Open Access This article is distributed under the terms of the Creative Commons Attribution Noncommercial License which permits any noncommercial use, distribution, and reproduction in any medium, provided the original author(s) and source are credited.

\section{References}

1. Amunts K, Kedo O, Kindler M, Pieperhoff P, Mohlberg H, Shah NJ, Habel U, Schneider F, Zilles K (2005) Cytoarchitectonic mapping of the human amygdala, hippocampal region and entorhinal cortex: intersubject variability and probability maps. Anat Embryol (Berl) 210:343-352

2. Apkarian AV, Bushnell MC, Treede RD, Zubieta JK (2005) Human brain mechanisms of pain perception and regulation in health and disease. Eur J Pain 9:463-484

3. Augustine JR (1996) Circuitry and functional aspects of the insular lobe in primates including humans. Brain Res Brain Res Rev 22:229-244

4. Ball T, Rahm B, Eickhoff SB, Schulze-Bonhage A, Speck O, Mutschler I (2007) Response properties of human amygdala subregions: evidence based on functional MRI combined with probabilistic anatomical maps. PLoS ONE 2:e307

5. Baron R, Baron Y, Disbrow E, Roberts TP (1999) Brain processing of capsaicin-induced secondary hyperalgesia: a functional MRI study. Neurology 53:548-557

6. Beekman AT, Deeg DJ, Van Limbeek J, Braam AW, De Vries MZ, Van Tilburg W (1997) Criterion validity of the Center for Epidemiologic Studies Depression scale (CES-D): results from a community-based sample of older subjects in The Netherlands. Psychol Med 27:231-235
7. Beghi E, Allais G, Cortelli P, D'Amico D, De Simone R, d'Onofrio F, Genco S, Manzoni GC, Moschiano F, Tonini MC, Torelli P, Quartaroli M, Roncolato M, Salvi S, Bussone G (2007) Headache and anxiety-depressive disorder comorbidity: the HADAS study. Neurol Sci 28(Suppl 2):S217-S219

8. Bentley DE, Watson A, Treede RD, Barrett G, Youell PD, Kulkarni B, Jones AK (2004) Differential effects on the laser evoked potential of selectively attending to pain localisation versus pain unpleasantness. Clin Neurophysiol 115:1846-1856

9. Bingel U, Quante M, Knab R, Bromm B, Weiller C, Buchel C (2002) Subcortical structures involved in pain processing: evidence from single-trial fMRI. Pain 99:313-321

10. Bornhovd K, Quante M, Glauche V, Bromm B, Weiller C, Buchel C (2002) Painful stimuli evoke different stimulus-response functions in the amygdala, prefrontal, insula and somatosensory cortex: a single-trial fMRI study. Brain 125:1326-1336

11. Breslau N, Lipton RB, Stewart WF, Schultz LR, Welch KM (2003) Comorbidity of migraine and depression: investigating potential etiology and prognosis. Neurology 60:1308-1312

12. Casey KL, Minoshima S, Berger KL, Koeppe RA, Morrow TJ, Frey KA (1994) Positron emission tomographic analysis of cerebral structures activated specifically by repetitive noxious heat stimuli. J Neurophysiol 71:802-807

13. Cassell MD, Freedman LJ, Shi C (1999) The intrinsic organization of the central extended amygdala. Ann N Y Acad Sci 877:217-241

14. Chapman CR, Casey KL, Dubner R, Foley KM, Gracely RH, Reading AE (1985) Pain measurement: an overview. Pain 22:1-31

15. Chibnall JT, Tait RC (1994) The pain disability index: factor structure and normative data. Arch Phys Med Rehabil 75:1082-1086

16. Christmann C, Koeppe C, Braus DF, Ruf M, Flor H (2007) A simultaneous EEG-fMRI study of painful electric stimulation. Neuroimage 34:1428-1437

17. Coghill RC, Sang CN, Maisog JM, Iadarola MJ (1999) Pain intensity processing within the human brain: a bilateral, distributed mechanism. J Neurophysiol 82:1934-1943

18. Coghill RC, Talbot JD, Evans AC, Meyer E, Gjedde A, Bushnell MC, Duncan GH (1994) Distributed processing of pain and vibration by the human brain. J Neurosci 14:4095-4108

19. Craig AD, Reiman EM, Evans A, Bushnell MC (1996) Functional imaging of an illusion of pain. Nature 384:258-260

20. Desgranges B, Baron JC, Lalevee C, Giffard B, Viader F, de La Sayette V, Eustache F (2002) The neural substrates of episodic memory impairment in Alzheimer's disease as revealed by FDGPET: relationship to degree of deterioration. Brain 125:1116-1124

21. Dolan RJ (2007) The human amygdala and orbital prefrontal cortex in behavioural regulation. Philos Trans R Soc Lond B Biol Sci 362:787-799

22. Donnet A, Lanteri-Minet M, Guegan-Massardier E, Mick G, Fabre N, Geraud G, Lucas C, Navez M, Valade D (2007) Chronic cluster headache: a French clinical descriptive study. J Neurol Neurosurg Psychiatry 78:1354-1358

23. Dotson VM, Davatzikos C, Kraut MA, Resnick SM (2009) Depressive symptoms and brain volumes in older adults: a longitudinal magnetic resonance imaging study. J Psychiatry Neurosci 34:367-375

24. Dworkin RH, Gitlin MJ (1991) Clinical aspects of depression in chronic pain patients. Clin J Pain 7:79-94

25. Frank E, Prien RF, Jarrett RB, Keller MB, Kupfer DJ, Lavori PW, Rush AJ, Weissman MM (1991) Conceptualization and rationale for consensus definitions of terms in major depressive disorder. Remission, recovery, relapse, and recurrence. Arch Gen Psychiatry 48:851-855

26. Geisser ME, Roth RS, Robinson ME (1997) Assessing depression among persons with chronic pain using the Center for 
Epidemiological Studies-Depression Scale and the Beck Depression Inventory: a comparative analysis. Clin J Pain 13:163-170

27. Gentili C, Panicucci P, Guazzelli M (2005) Psychiatric comorbidity and chronicisation in primary headache. J Headache Pain 6:338-340

28. Gispert JD, Pascau J, Reig S, Martinez-Lazaro R, Molina V, Garcia-Barreno P, Desco M (2003) Influence of the normalization template on the outcome of statistical parametric mapping of PET scans. Neuroimage 19:601-612

29. Gonzalez-Lima F, Scheich H (1986) Classical conditioning of tone-signaled bradycardia modifies 2-deoxyglucose uptake patterns in cortex, thalamus, habenula, caudate-putamen and hippocampal formation. Brain Res 363:239-256

30. Gündel H, Tölle TR (2005) How physical pain may interact with psychiological pain: evidence for a mutual neurobiological basis of emotions and pain. In: Carr DB, Loeser JD, Morris DB (eds) Narrative, pain, and suffering. IASP PRESS, Seattle, pp 87-112

31. Hamann SB, Ely TD, Grafton ST, Kilts CD (1999) Amygdala activity related to enhanced memory for pleasant and aversive stimuli. Nat Neurosci 2:289-293

32. Henningsen P, Lowe B (2006) Depression, pain, and somatoform disorders. Curr Opin Psychiatry 19:19-24

33. Hjornevik T, Jacobsen LM, Qu H, Bjaalie JG, Gjerstad J, Willoch $\mathrm{F}$ (2008) Metabolic plasticity in the supraspinal pain modulating circuitry after noxious stimulus-induced spinal cord LTP. Pain $140: 456-464$

34. International Headache Society (2004) The International Classification of Headache Disorders, 2nd edn. Cephalalgia 24(Suppl 1):9-160

35. Jensen RM, Lyngberg A, Jensen RH (2007) Burden of cluster headache. Cephalalgia 27:535-541

36. Jorge RE, Leston JE, Arndt S, Robinson RG (1999) Cluster headaches: association with anxiety disorders and memory deficits. Neurology 53:543-547

37. Karsdorp PA, Vlaeyen JW (2009) Active avoidance but not activity pacing is associated with disability in fibromyalgia. Pain 147:29-35

38. Katsarava Z, Ayzenberg I, Sack F, Limmroth V, Diener HC, Kaube H (2006) A novel method of eliciting pain-related potentials by transcutaneous electrical stimulation. Headache 46:1511-1517

39. Kennedy SH, Evans KR, Kruger S, Mayberg HS, Meyer JH, McCann S, Arifuzzman AI, Houle S, Vaccarino FJ (2001) Changes in regional brain glucose metabolism measured with positron emission tomography after paroxetine treatment of major depression. Am J Psychiatry 158:899-905

40. Kim H, Somerville LH, Johnstone T, Alexander AL, Whalen PJ (2003) Inverse amygdala and medial prefrontal cortex responses to surprised faces. Neuroreport 14:2317-2322

41. Kohno T, Shiga T, Toyomaki A, Kusumi I, Matsuyama T, Inoue T, Katoh C, Koyama T, Tamaki N (2007) Effects of lithium on brain glucose metabolism in healthy men. J Clin Psychopharmacol 27:698-702

42. Konarski JZ, Kennedy SH, McIntyre RS, Rafi-Tari S, Soczynska JK, Mayberg HS (2007) Relationship between regional brain metabolism, illness severity and age in depressed subjects. Psychiatry Res 155:203-210

43. LeDoux J (2003) The emotional brain, fear, and the amygdala. Cell Mol Neurobiol 23:727-738

44. LeDoux JE (2000) Emotion circuits in the brain. Annu Rev Neurosci 23:155-184

45. Maihöfner C, Handwerker HO (2005) Differential coding of hyperalgesia in the human brain: a functional MRI study. Neuroimage 28:996-1006
46. Manning BH, Merin NM, Meng ID, Amaral DG (2001) Reduction in opioid- and cannabinoid-induced antinociception in rhesus monkeys after bilateral lesions of the amygdaloid complex. J Neurosci 21:8238-8246

47. Marcus DA (2003) Headache and other types of chronic pain. Headache 43:49-53

48. Mayberg HS (2007) Defining the neural circuitry of depression: toward a new nosology with therapeutic implications. Biol Psychiatry $61: 729-730$

49. McGaugh JL (2004) The amygdala modulates the consolidation of memories of emotionally arousing experiences. Annu Rev Neurosci 27:1-28

50. Mewes R, Rief W, Stenzel N, Glaesmer H, Martin A, Brahler E (2009) What is "normal" disability? An investigation of disability in the general population. Pain 142:36-41

51. Minoshima S, Berger KL, Lee KS, Mintun MA (1992) An automated method for rotational correction and centering of three-dimensional functional brain images. J Nucl Med 33:1579-1585

52. Minoshima S, Koeppe RA, Mintun MA, Berger KL, Taylor SF, Frey KA, Kuhl DE (1993) Automated detection of the intercommissural line for stereotactic localization of functional brain images. J Nucl Med 34:322-329

53. Mohr C, Binkofski F, Erdmann C, Buchel C, Helmchen C (2005) The anterior cingulate cortex contains distinct areas dissociating external from self-administered painful stimulation: a parametric fMRI study. Pain 114:347-357

54. Moulton EA, Pendse G, Morris S, Strassman A, Aiello-Lammens M, Becerra L, Borsook D (2007) Capsaicin-induced thermal hyperalgesia and sensitization in the human trigeminal nociceptive pathway: an fMRI study. Neuroimage 35:1586-1600

55. Murphy FC, Nimmo-Smith I, Lawrence AD (2003) Functional neuroanatomy of emotions: a meta-analysis. Cogn Affect Behav Neurosci 3:207-233

56. Nagel B, Gerbershagen HU, Lindena G, Pfingsten M (2002) Development and evaluation of the multidimensional German pain questionnaire. Schmerz 16:263-270

57. Pellicano C, Gallo A, Li X, Ikonomidou VN, Evangelou IE, Ohayon JM, Stern SK, Ehrmantraut M, Cantor F, McFarland HF, Bagnato F (2010) Relationship of cortical atrophy to fatigue in patients with multiple sclerosis. Arch Neurol 67:447-453

58. Peyron R, Laurent B, Garcia-Larrea L (2000) Functional imaging of brain responses to pain. A review, meta-analysis (2000). Neurophysiol Clin 30:263-288

59. Pollard CA (1984) Preliminary validity study of the pain disability index. Percept Mot Skills 59:974

60. Pringsheim T (2002) Cluster headache: evidence for a disorder of circadian rhythm and hypothalamic function. Can J Neurol Sci 29:33-40

61. Radloff LS (1977) The CES-D: A self-report symptom scale to detect depression in the general population. Appl Psychol Meas 3:385-401

62. Roberts RE, Vernon SW (1983) The Center for Epidemiologic Studies Depression Scale: its use in a community sample. Am J Psychiatry 140:41-46

63. Rocher AB, Chapon F, Blaizot X, Baron JC, Chavoix C (2003) Resting-state brain glucose utilization as measured by PET is directly related to regional synaptophysin levels: a study in baboons. Neuroimage 20:1894-1898

64. Sah P, Faber ES, Lopez De Armentia M, Power J (2003) The amygdaloid complex: anatomy and physiology. Physiol Rev 83:803-834

65. Salmon E, Perani D, Herholz K, Marique P, Kalbe E, Holthoff V, Delbeuck X, Beuthien-Baumann B, Pelati O, Lespagnard S, Collette F, Garraux G (2006) Neural correlates of anosognosia for 
cognitive impairment in Alzheimer's disease. Hum Brain Mapp 27:588-597

66. Schneider F, Habel U, Holthusen H, Kessler C, Posse S, MullerGartner HW, Arndt JO (2001) Subjective ratings of pain correlate with subcortical-limbic blood flow: an fMRI study. Neuropsychobiology 43:175-185

67. Sprenger T, Henriksen G, Valet M, Platzer S, Berthele A, Tolle TR (2007) Positron emission tomography in pain research: From the structure to the activity of the opiate receptor system. Schmerz 21:503-513

68. Sprenger T, Ruether K, Boecker H, Valet M, Berthele A, Pfaffenrath V, Woller A, Tolle T (2007) Altered metabolism in frontal brain circuits in cluster headache. Cephalalgia 27:1033-1042

69. Sprenger T, Valet M, Boecker H, Henriksen G, Spilker ME, Willoch F, Wagner KJ, Wester HJ, Tolle TR (2006) Opioidergic activation in the medial pain system after heat pain. Pain 122:63-67

70. Strigo IA, Simmons AN, Matthews SC, Craig AD, Paulus MP (2008) Association of major depressive disorder with altered functional brain response during anticipation and processing of heat pain. Arch Gen Psychiatry 65:1275-1284

71. Tait RC, Chibnall JT, Krause S (1990) The pain disability index: psychometric properties. Pain 40:171-182

72. Tait RC, Pollard CA, Margolis RB, Duckro PN, Krause SJ (1987) The pain disability index: psychometric and validity data. Arch Phys Med Rehabil 68:438-441

73. Tolle TR, Kaufmann T, Siessmeier T, Lautenbacher S, Berthele A, Munz F, Zieglgansberger W, Willoch F, Schwaiger M, Conrad
B, Bartenstein P (1999) Region-specific encoding of sensory and affective components of pain in the human brain: a positron emission tomography correlation analysis. Ann Neurol 45:40-47

74. Torelli P, Castellini P, Cucurachi L, Devetak M, Lambru G, Manzoni GC (2006) Cluster headache prevalence: methodological considerations. A review of the literature. Acta Biomed 77:4-9

75. Torelli P, Manzoni GC (2005) Behavior during cluster headache. Curr Pain Headache Rep 9:113-119

76. Torelli P, Manzoni GC (2003) Pain and behaviour in cluster headache. A prospective study and review of the literature. Funct Neurol 18:205-210

77. Treede RD, Kenshalo DR, Gracely RH, Jones AK (1999) The cortical representation of pain. Pain 79:105-111

78. Valet M, Sprenger T, Boecker H, Willoch F, Rummeny E, Conrad B, Erhard P, Tolle TR (2004) Distraction modulates connectivity of the cingulo-frontal cortex and the midbrain during pain-an fMRI analysis. Pain 109:399-408

79. Vranken JH, Dijkgraaf MG, Kruis MR, van der Vegt MH, Hollmann MW, Heesen M (2008) Pregabalin in patients with central neuropathic pain: a randomized, double-blind, placebocontrolled trial of a flexible-dose regimen. Pain 136:150-157

80. Whalen PJ, Shin LM, McInerney SC, Fischer H, Wright CI, Rauch SL (2001) A functional MRI study of human amygdala responses to facial expressions of fear versus anger. Emotion 1:70-83

81. Zubieta JK, Smith YR, Bueller JA, Xu Y, Kilbourn MR, Jewett DM, Meyer CR, Koeppe RA, Stohler CS (2001) Regional mu opioid receptor regulation of sensory and affective dimensions of pain. Science 293:311-315 